\title{
Discurso inaugural del año académico 2021
}

\section{Academic Year opening speech}

\author{
José Halabe-Cherem* \\ División de Estudios de Posgrado, Facultad de Medicina, Universidad Nacional Autónoma de México, Ciudad de México, México
}

Distinguidas académicas, académicos, señoras y señores

Miembros del presídium

El día de hoy se inaugura el año académico 2021 de la Academia Nacional de Medicina de México (ANMM) y estoy consciente de lo que representa este compromiso. La institución cuenta con más de 160 años de vida que reflejan la historia de múltiples aspectos de la salud en México. Por la ANMM han transitado los personajes más brillantes de la medicina mexicana, entre ellos los presidentes que aquí vemos retratados, así como los académicos talentosos que formaron parte de sus mesas directivas y, en general, cada uno de los miembros de esta institución.

La ANMM recoge esa tradición y la actualiza respondiendo a los desafíos del presente y futuro. Por décadas, la institución ha sido una de las voces más reconocidas en temas de salud pública y esto se concreta en su representación en los órganos de decisión más importantes del sistema de salud nacional. Por otro lado, la Academia es un foro reconocido para presentar investigaciones clínicas, básicas y sociomédicas de vanguardia, las cuales son expuestas y comentadas por los académicos de manera semanal. La ANMM también cuenta con una de las publicaciones médicas más importantes de México, América Latina y el mundo, la Gaceta Médica de México, que se ha editado en forma ininterrumpida y contiene trabajos relevantes que analizan los saberes propios de nuestra disciplina en el campo de la salud.

La herencia que recibimos nos da una gran plataforma que nos permite continuar creciendo $y$ aportando mejores ideas para coadyuvar en proyectos que incidan en la práctica médica. La ANMM está estructurada por sitiales diferenciados en especialidades que se ocupan de asuntos académicos, asistenciales y de investigación relativos a sus conocimientos y problemáticas específicas. Uno de los objetivos es que participe en forma activa el mayor número de académicos de nuestra institución, ya que ellos son expertos en sus áreas profesionales.

La propuesta de esta mesa directiva es darles la voz a los académicos y visibilizar sus conocimientos. Con este objetivo formaremos comités por cada grupo de especialidad, para que planteen las problemáticas y posibles soluciones a las que se enfrentan sus áreas correspondientes, de esta manera pretendemos ser inclusivos y aprovechar el talento en pro de la medicina mexicana. Con esta intención, en las próximas semanas estaremos convocando a varios grupos de académicos de toda la República Mexicana para formar estos comités. La finalidad es discutir y hacer propuestas de cambio en consensos sobre políticas de salud. Al mismo tiempo, fortaleceremos el trabajo de los comités ya existentes, los cuales han aportado ideas valiosas en los últimos años. Invito a los miembros de la Academia que estén interesados en participar a que se acerquen a nosotros para integrarse a estos grupos de trabajo.

Una de las características de la Academia es su constitución plural. En la Academia convergen diversas organizaciones, posturas ideológicas y formas de pensar variadas sobre el mundo contemporáneo, que serán discutidas y ponderadas en asambleas generales
Correspondencia:

0016-3813/@ 2020 Academia Nacional de Medicina de México, A.C. Publicado por Permanyer. Este es un artículo open access bajo la licencia
*José Halabe-Cherem

E-mail: jhalabe@unam.mx

Fecha de recepción: 22-03-2021

Fecha de aceptación: 24-03-2021

CC BY-NC-ND (http://creativecommons.org/licenses/by-nc-nd/4.0/)
Gac Med Mex. 2021;157:123-124

Disponible en PubMed

www.gacetamedicademexico.com 
extraordinarias, en la mesa directiva y con el cuerpo consultivo integrado por nuestros expresidentes, a quienes les solicitaremos su opinión por el bagaje de experiencia con el que cuentan. Una vez consensuada la postura, la Academia podrá emitir su opinión a las instancias correspondientes.

En relación con las actividades de la ANMM, se continuarán las sesiones semanales programadas con un año de anticipación, como lo podrán ver en el programa que se encuentra en el vestíbulo de este auditorio; además, en estos mismos foros se presentarán los trabajos de ingreso de los nuevos académicos. Se realizarán las sesiones extramuros con las diferentes instituciones de salud, tanto públicas como privadas. Esperamos que estas sesiones puedan realizarse de forma presencial y virtual de manera sincrónica, para fomentar el intercambio dialógico. En esta pandemia hemos aprendido que las comunicaciones virtuales pueden tener más audiencia y tienen la posibilidad de ser consultadas en cualquier momento.

Fortaleceremos la educación a distancia por medio de videos dirigidos al médico general y a las diferentes especialidades médicas. Además, continuaremos con la actualización sobre la pandemia de COVID-19; desde marzo de 2020 a la fecha hemos comunicado al cuerpo médico y a la población en general los avances científicos que surgen y se transforman. Estaremos atentos a las enfermedades emergentes y reemergentes, para que con nuestros académicos expertos propongamos lineamientos 0 medidas a seguir. Continuaremos trabajando estrechamente con la Universidad Nacional Autónoma de México (UNAM) en general y con la Facultad de Medicina en particular, en diversos programas educativos tanto en el pregrado como en el posgrado. También estaremos colaborando en estos mismos aspectos con escuelas y facultades de medicina del país.

La Gaceta Médica, como órgano oficial de la ANMM, es una revista cuyo índice de impacto aumenta día a día. Las visitas son cada vez más numerosas en todas partes del mundo, ya que los artículos son publicados en inglés y en español. Hoy en día, la revista es accesible únicamente en línea, lo que ahorra tanto recursos naturales como económicos. El rigor en el proceso de selección de los artículos sigue siendo muy estricto y así se continuará con el objeto de mantener la calidad editorial. La Gaceta tiene un equilibrio en su contenido (editoriales, presentación de casos clínicos, monografías, artículos de investigación y cartas al editor). Sugeriremos que se agregue una sección denominada "artículos de reflexión" para dar cabida a propuestas analíticas de interés en el campo de la salud. La lista de destacados revisores que colaboran con la Gaceta Médica será fortalecida con nuevos miembros, para darle dinamismo a la discusión de las ideas. El comité editorial de la ANMM valorará, discutirá y, en su caso, aprobará la publicación de libros y materiales impresos y digitales avalados por nuestra organización.

En relación con los premios otorgados en forma anual se agregará uno nuevo destinado a reconocer los méritos en la educación en ciencias de la salud. El fin es estimular la labor que ejercen los docentes en la transmisión del conocimiento y la formación de recursos humanos que permitan la reproducción del campo médico.

La ANMM puede constituirse en un nodo fuerte en la red de instituciones nacionales e internacionales de salud. Hoy en día, nuestros académicos ocupan puestos importantes en la vida pública del país, por ejemplo, el secretario de salud, el rector de la UNAM, el embajador permanente de México ante las Naciones Unidas, el director de la Facultad de Medicina de la UNAM, entre otros, con quienes interactuaremos para potenciar el trabajo académico de la Academia. En este mismo sentido, robusteceremos las relaciones con las academias nacionales de Estados Unidos, España y Francia, así como con diversos países de Centroamérica y Sudamérica con los cuales hemos concretado algunos acuerdos.

Haber trabajado durante estos dos años como vicepresidente me permitió conocer de cerca la dinámica de la institución. El trabajo cotidiano, los logros y las problemáticas con las que nos enfrentamos nos hicieron conformar un equipo solidario que, más allá de nuestra organización, generó fuertes lazos de amistad. La mesa que hoy conformamos - integrada por el doctor Germán Fajardo como vicepresidente, la doctora Mayela Rodríguez como secretaria, el doctor Miguel Abdo como tesorero y el doctor José Flores como secretario adjunto, así como todo el equipo de la ANMM - está comprometida a trabajar arduamente en beneficio de la medicina mexicana.

Distinguidas académicas y académicos, los invito a que trabajemos al unísono y a que aportemos nuestros conocimientos y experiencia para hacer grande a la ANMM.

Les agradezco su atención, su confianza y sé que contaré con cada uno de ustedes. 